\title{
Effect of smoking status on total energy expenditure
}

\author{
David P Bradley ${ }^{1}$, Lindsey A Johnson ${ }^{2,3}$, Zhumin Zhang ${ }^{2}$, Amy F Subar ${ }^{5}$, Richard P Troiano ${ }^{5}$, Arthur Schatzkin ${ }^{4}$, \\ Dale A Schoeller ${ }^{2^{*}}$
}

\begin{abstract}
Individuals who smoke generally have a lower body mass index (BMI) than nonsmokers. The relative roles of energy expenditure and energy intake in maintaining the lower BMI, however, remain controversial. We tested the hypothesis that current smokers have higher total energy expenditure than never smokers in 308 adults aged 40-69 years old of which 47 were current smokers. Energy expenditure was measured by doubly labeled water during a two week period in which the subjects lived at home and performed their normal activities. Smoking status was determined by questionnaire. There were no significant differences in mean BMI (mean \pm SD) between smokers and never smokers for either males $\left(27.8+5.1 \mathrm{~kg} / \mathrm{m}^{2} \mathrm{vs} .27 .5+4.0 \mathrm{~kg} / \mathrm{m}^{2}\right)$ or females $\left(26.5+5.3 \mathrm{~kg} / \mathrm{m}^{2} \mathrm{vs}\right.$. $\left.28.1+6.6 \mathrm{~kg} / \mathrm{m}^{2}\right)$, although the difference in females was of similar magnitude to previous reports. Similarly, total energy expenditure of male smokers $(3069+764 \mathrm{kcal} / \mathrm{d})$ was not significantly different from that of never smokers $(2854+468 \mathrm{kcal} / \mathrm{d})$, and that of female smokers $(2266+387 \mathrm{kcal} / \mathrm{d})$ was not different from that of never smokers $(2330+415 \mathrm{kcal} / \mathrm{d})$. These findings did not change after adjustment for age, fat-free mass and self-reported physical activity. Using doubly labeled water, we found no evidence of increased energy expenditure among smokers, however, it should be noted that BMI differences in this cohort also did not differ by smoking status.
\end{abstract}

\section{Introduction}

Numerous cross-sectional studies have indicated that body mass index (BMI) is lower in cigarette smokers than in nonsmokers [1-3], and that leanness correlated directly with duration, but not intensity of smoking, with longer duration associated with lower BMI [4-6]. Recent statistical analyses of data sets from both the 2005-2006 National Health and Nutrition Examination Survey (NHANES) [2] and the 2005 National Health Interview Survey [7] confirmed findings from prior studies indicating that smokers weighed significantly less than nonsmokers. Individuals who stop smoking have been reported to gain weight after they quit, and this prospect can discourage tobacco cessation $[1,3,6]$. Women seem to be somewhat more susceptible to weight gain following smoking cessation than men. In a 10 year study, the mean weight gain attributable to cessation was $5.0 \mathrm{~kg}$ in women and $4.4 \mathrm{~kg}$ in men [3]. Multiple studies have

\footnotetext{
* Correspondence: dschoell@nutrisci.wisc.edu

2Department of Nutritional Sciences, University of Wisconsin, Madison, WI, USA

Full list of author information is available at the end of the article
}

shown that $33-75 \%$ of ex-smokers reported weight gain within the first year of cessation [8].

While the exact cause of this weight gain is unclear, two hypotheses, which are not mutually exclusive, are frequently proposed. The first is that smoking increases energy expenditure due to nicotine's effects in raising metabolic rate, resulting in decreased energy expenditure with cessation [8-10]. In 1986, Hofstetter et al. reported that 24-hour energy expenditure increased in smokers by $140-200 \mathrm{kcal} /$ day on a day with smoking compared to a day without smoking, and no corresponding change in mean basal metabolic rate [11]. Further studies have since yielded conflicting results with most finding an increase in resting metabolic rate (RMR) shortly after nicotine administration. Walker et al. found a $6 \%$ increase in RMR after 20 minutes of smoking [12] and Dalloso et al. documented a 3\% increase in RMR after smoking a single cigarette [10]. Several studies, however, failed to find a corresponding increase in RMR measured either before or after smoking a single cigarette before they ceased smoking $[13,14]$.

The second hypothesis is that smoking alters energy intake by inducing an anorexic effect [9] and, by 
extension, smoking cessation leads to weight gain due to increased intake [15]. Findings on this subject vary and results are also inconsistent. In a study by Jessen et al., during a two hour period, nicotine administration was negatively associated with hunger and food consumption and positively associated with satiety [16]. Perkins et al. found increased satiety and lower caloric intakes following nicotine administration [17]. However, in another study, the same authors found higher caloric intakes with nicotine administration [18].

Unfortunately, the second hypothesis is difficult to test because self-report tools were used to measure intake. Numerous studies have shown that self-reported dietary records are prone to error, usually in the direction of underreporting [19]. In addition, the first hypothesis has historically been difficult to test, with the exception of short-term measurements of RMR over a period of minutes or hours. This is because measuring total energy expenditure (TEE) under free-living conditions was difficult in the past [20]. This has changed, however, with the development of the doubly labeled water (DLW) method for measuring TEE [21]. This method is based on the observation that after a loading dose of water labeled with deuterium and ${ }^{18} \mathrm{O}$, the deuterium is eliminated from the body as water, while the ${ }^{18} \mathrm{O}$ is eliminated as water and carbon dioxide. The difference between the elimination rates is therefore proportional to carbon dioxide production and hence energy expenditure [21]. The doubly labeled water technique provides a measure of TEE which includes RMR, thermic effects of meals (TEM) and physical activity energy expenditure (PAEE). Moreover, the DLW method averages TEE over a period of days to two weeks thus providing a counterpart to energy intake in assessing contributions to energy balance [21].

Utilizing DLW, Warwick and Baines reported no difference in energy expenditure between smokers and non-smokers. This study, however, included only 11 smokers and 10 nonsmokers and thus had limited power [22]. We calculate the standard error for the difference in TEE between smokers and nonsmokers in the study of Warwick and Barns to be $249 \mathrm{kcal} / \mathrm{d}$ and thus the smallest difference they could have expected to identify $(\mathrm{P}<0.05)$ with $80 \%$ power would have been nearly $700 \mathrm{kcal} / \mathrm{d}$.

We analyzed data from the National Cancer Institute's (NCI) Observing Protein and Energy Nutrition (OPEN) Study, which was conducted to assess the structure of measurement error in self-reported dietary assessment instruments. In OPEN, TEE was measured by DLW in 484 adults $[23,24]$. Each participant also reported their smoking status, thus providing an opportunity to test the hypothesis that the TEE of smokers is greater than that of never-smokers.

\section{Methods}

\section{Subjects}

Of the original 484 adults (age 40-69 years) who participated in the OPEN study, which was conducted during 1999, 10 were excluded because they lacked smoking data, 150 were excluded because they had smoked at one time, but were currently non-smokers, and 33 were excluded because of missing energy expenditure data [23]. The remaining 304 participants (158 male, 146 female), 47 of which (20 male, 27 female) were current smokers were included in the analysis. The majority of the participants in OPEN were white males and females with some college education or higher [25]. The study was approved by the institutions involved and participants provided signed informed consent.

\section{Study Design}

The OPEN Study evaluated the structure of dietary measurement error in food frequency questionnaires (FFQs) and 24-hour dietary recalls (24 HRs) by using DLW and urinary nitrogen as biomarkers of TEE and protein. Full details can be found elsewhere, including dietary data $[25,26]$. In brief, a randomized sample of 5,000 individuals aged 40-69 years of age within the Washington DC area was contacted via telephone. After an initial telephone encounter, participants meeting inclusion criteria were invited to a series of 3 clinic visits. DLW studies were performed between the first visit and second visit (11-14 days later).

DLW studies were performed using a five-urine-specimen protocol. DLW was administered orally at the first visit at a dose of $2 \mathrm{~g}$ of 10 atom percent ${ }^{18} \mathrm{O}$ labeled water and $0.12 \mathrm{~g}$ of 99.9 atom percent ${ }^{2} \mathrm{H}$ labeled water per kilogram of estimated total body water along with a $50-\mathrm{ml}$ rinse of the dose bottle. Urine specimens were then collected at 2,3, and 4 hours after the dose with the 2 hour specimen being discarded. Urine was again collected twice approximately 14 days later. TEE was calculated with the modified Weir equation, assuming a respiratory quotient of 0.86 . Isotope analysis was performed as previously described [25].

Participants reported their smoking status and physical activity level on questionnaires. Smoking status was based on the number of cigarettes smoked during the lifetime. Those who had smoked less than 100 cigarettes in their lifetime were classified as never-smokers and those who had smoked more than 100 cigarettes were classified as smokers. Those who reported quitting smoking were classified as past smokers and those who did not report quitting were classified as current smokers. Only never smokers and current smokers were included in the study. The DLW method thus provided a measure of total daily energy expenditure averaged over a period 11 to 14 days 
during which there were no restrictions or instructions regarding smoking.

Physical activity was assessed with the OPEN Study Physical Activity Questionnaire, the same questionnaire that was used in NHANES 2001-2002 [27]. Participants reported the duration and frequency of specific domains of physical activity, which were translated into METminutes of physical activity per week.

The FFQ utilized in the OPEN study was the Diet History Questionnaire (DHQ) (available at http://www.riskfactor.cancer.gov/DHQ/), developed and evaluated at NCI [25]. This questionnaire assessed the frequency of intake for 124 individual foods/food group items during the preceding 12 months and evaluated the portion size of most items. Data from the DHQ was analyzed by Diet"Calc Software (version 1.4.3, 2005, National Cancer Institute, Bethesda, MD).

The 24 HR used in the OPEN Study was a standardized five-pass method, developed by the US Department of Agriculture for use in national dietary surveillance [26].

Fat free mass (FFM) was calculated indirectly based on TBW from the deuterium and $\mathrm{O}^{18}$ dilution spaces and body mass.

\section{Statistical Analysis}

All statistical analyses were performed using SAS (version 9.13, SAS Institute, Inc, Cary NC). Male and female participants were analyzed separately using a $\mathrm{T}$ test to assess smoking-group differences for continuous outcomes. Multiple regression models were fitted to compare the TEE of current smokers to never smokers including four variables significantly influencing TEE: gender, age (years), fat free mass (FFM) (kg), and physical activity (PA) (MET minutes/week). Least-squares (LS) means were also calculated and compared between smokers and non-smokers. All regression analyses were performed using the PROC GLM procedure in SAS. An $\alpha$ value of $<0.05$ was considered statistically significant.

\section{Results}

Subject characteristics are shown in Table 1. Among both males and females, no significant differences were detected between smokers and non-smokers for age, height, weight, BMI, FFM, or reported PA. Consistent with other studies, the female participants, on average, expended less energy than the males $(2319+/-409 \mathrm{kcal} /$ day vs. $2882+/-518 \mathrm{kcal} /$ day, $\mathrm{p}<0.001$, Table 2 ). When categorized by smoking status, unadjusted TEE in female smokers and never smokers averaged $2266 \pm 387$ $\mathrm{kcal} /$ day and $2330 \pm 415 \mathrm{kcal} /$ day respectively and was not significantly different $(\mathrm{p}=0.46)$. Among males, unadjusted average TEE was $3069+764 \mathrm{kcal} / \mathrm{d}$ in smokers and $2854+468 \mathrm{kcal} / \mathrm{d}$ in never smokers, also not significantly different $(\mathrm{p}=0.08)$.

FFM and age were significantly correlated with TEE in both genders (Table 3). The effect of smoking status on TEE is shown in Table 4. No difference in least-square means was found.

Table 5 shows the multiple regression coefficients for several factors related to TEE. Smoking was not significantly associated with TEE in either males or females. FFM was the strongest factor positively associated with TEE in both males and females, while age and PA were positively associated in males, but not in females.

\section{Discussion}

This is the largest study to compare total energy expenditure between free-living smokers and never-smokers using DLW. In so doing, we greatly strengthen the findings of Warwick and Baines, who also reported no difference in energy expenditure between smokers and non-smokers $(2877+/-496 \mathrm{kcal} / \mathrm{d}$ vs. $2541+/-628 \mathrm{kcal} /$ d), by including 47 smokers and 257 non-smokers compared to their small sample of 11 and 10 smokers and non-smokers [22]. Our larger sample, therefore, allowed us to detect a difference of $216 \mathrm{kcal} / \mathrm{d}$ compared with $700 \mathrm{kcal} / \mathrm{d}$ for the smaller study. Based on the unadjusted TEE value, the $95 \%$ CL for the TEE difference between male smokers and never smokers was -28 to $458 \mathrm{kcal} / \mathrm{d}$

Table 1 Subject Characteristics

\begin{tabular}{lllll}
\hline & Smokers $(\mathbf{n}=\mathbf{2 0})$ & $\begin{array}{l}\text { Males } \\
\text { Never-Smokers }(\mathbf{n}=\mathbf{1 3 8})\end{array}$ & Smokers $(\mathbf{n}=\mathbf{2 7})$ & $\begin{array}{c}\text { Females } \\
\text { Never-Smokers }(\mathbf{n}=\mathbf{1 1 9})\end{array}$ \\
\hline Age $(\mathrm{y})$ & $50.6 \pm 8.7$ & $53.4 \pm 8.3$ & $53.6 \pm 8.1$ & $52.2 \pm 7.9$ \\
Height $(\mathrm{cm})$ & $177.4 \pm 7.7$ & $176.3 \pm 7.9$ & $164.6 \pm 6.6$ & $162.3 \pm 6.7$ \\
Weight $(\mathrm{kg})$ & $87.7 \pm 18.9$ & $85.4 \pm 13.9$ & $71.8 \pm 16$ & $74.1 \pm 18.3$ \\
BMI $\left(\mathrm{kg} / \mathrm{m}^{2}\right)$ & $27.8 \pm 5.1$ & $27.5 \pm 4.0$ & $26.5 \pm 5.3$ & $28.1 \pm 6.6$ \\
FFM $(\mathrm{kg})$ & $60 \pm 11.4$ & $58 \pm 7.9$ & $42.8 \pm 7.1$ & $42.4 \pm 6.7$ \\
& & & $1467 \pm 1679$ & $1516 \pm 1387$ \\
\hline
\end{tabular}

Values are written as mean \pm standard deviation. FFM $=$ Fat Free Mass. 
Table 2 TEE in smokers and non-smokers

\begin{tabular}{lllll}
\hline & Overall & Never smokers & Current smokers & Difference \\
\hline Males & $2882 \pm 518$ & $2854 \pm 468$ & $3069 \pm 764$ & $214(p=0.08)$ \\
Females & $2319 \pm 409$ & $2330 \pm 415$ & $2266 \pm 387$ & $64(p=0.46)$ \\
\hline
\end{tabular}

Values are written as mean +/- standard deviation in $\mathrm{kcal} /$ day. The number of subjects is the same as in Table 1.

and among females the $95 \% \mathrm{CL}$ of the difference was -237 to $109 \mathrm{kcal} / \mathrm{d}$. TEE, however, was strongly correlated with FFM and thus should be adjusted for FFM as well as age [23]. After adjustment, the 95\% CL for TEE in male and female smokers compared to never smokers was -64 to $246 \mathrm{kcal} / \mathrm{d}$ and -193 to $29 \mathrm{kcal} / \mathrm{d}$, respectively.

Other investigators have compared the energy requirements of smokers and non-smokers using dietary records with mixed results [28-35]. Such conflicting findings are not surprising in light of data showing that many individuals under-report their dietary energy intake by amounts often in excess of $15 \%$ indicating that the use of selfreported energy intake as a proxy measure of energy expenditure can be problematic $[24,36]$. In contrast, the DLW method has been carefully validated against measured TEE in a metabolic chamber and shown to be accurate within $1-2 \%$ with a coefficient of variation of 4-7\% [37].

Our finding of no significant difference in the TEE between current smokers and never smokers appears inconsistent with previous studies indicating that the RMR component of TEE is higher in smokers than non-smokers. For example, following multiple administrations of two nicotine doses to eighteen male smokers, Perkins et al. found that RMR acutely increases $3 \%$ above placebo after both moderate and low doses [38]. Likewise, Dallosso and James found that metabolic levels were elevated by $2.8 \%$ and $1.5 \%, 1-30$ and 31-60 min after smoking [10]. This increase appears to be acute rather than long-term. No animal studies have found a significant increase in long-term RMR after frequent exposure to cigarette smoke or nicotine $[39,40]$. Similarly, most human studies

Table 3 Pearson's correlation between TEE and related factors

\begin{tabular}{lcc}
\hline Factor & Correlation coefficient $(\mathbf{r})$ & $\mathbf{p}$-value \\
\hline Females & & \\
FFM (kg) & 0.75 & $\mathrm{p}<0.001$ \\
Age (y) & -0.34 & $\mathrm{p}<0.001$ \\
SR PA (MET*h) & 0.13 & $\mathrm{p}=0.13$ \\
Males & & \\
FFM (kg) & 0.76 & $\mathrm{p}<0.001$ \\
Age (y) & -0.21 & $\mathrm{p}=0.001$ \\
SR PA (MET*h) & 0.12 & $\mathrm{p}=0.16$ \\
\hline
\end{tabular}

The number of subjects is the same as in Table 1. SR PA = Self reported physical activity in mets/hour. found that smoking has insignificant long-term effects on $\operatorname{RMR}[13,14,40]$.

Unfortunately, RMR was not measured in the OPEN Study and thus we cannot direct compare results with regard to RMR. We can, however, calculate the effect of a short-term post-smoking percentage change in RMR to TEE. Assuming that smoking causes a 3 to $5 \%$ increase in RMR for up to $1 \mathrm{~h}$ after smoking, we would predict that a person who smokes a pack a day of cigarettes would have an increase in TEE of 30 to $50 \mathrm{kcal} /$ day. This small change is inside the confidence interval for our results in males and too small to detect. In females, however, we can reject the hypothesis that smoking causes a $30-50 \mathrm{kcal} / \mathrm{d}$ higher TEE in females. It should be noted, however, that our results are not necessarily inconsistent with a small increase in RMR. If one assumes that smoking is primarily a sedentary activity, then it is possible that the time spent smoking leads to reductions in physical activity that may compensate any potential increase in RMR associated with smoking. To test for this possibility, we also adjusted TEE for self-reported physical activity, but that adjustment had no influence on the results. Self-reported physical activity, however, is also subject to reporting error and thus our conclusion regarding this hypothesis is weak [41].

One limitation of the DLW technique is that it measures $\mathrm{CO}_{2}$ production and inhaled cigarette smoke contains $\mathrm{CO}_{2}$ produced from the burning of the tobacco [38]. Thus $\mathrm{CO}_{2}$ that is absorbed by the body will result in an inherent overestimation of energy expenditure in the DLW based measurement. Assuming that the consumed portion of each cigarette contains $0.7 \mathrm{~g}$ of combustible material and that the smoker inhales two-thirds of the $\mathrm{CO}_{2}$ produced by the cigarette, smoking two packs a day would produce an error of about $0.6 \mathrm{~mol}$ of $\mathrm{CO}_{2}$ per day or $2-4 \%$ of true $\mathrm{CO}_{2}$ production. Thus, heavy smoking is expected to result in an overestimate of $\mathrm{CO}_{2}$ production and therefore energy expenditure [38]. This limitation of the DLW method, however, does not alter our conclusion that smoking does not increase energy expenditure compared to never smokers, as correction for inhaled $\mathrm{CO}_{2}$ would act to further reduce the TEE of our smokers by 45 to $115 \mathrm{kcal} /$ day.

A second limitation of this analysis is that the OPEN cohort is not a representative sample. In particular, the male participants, who were classified as current smokers, did not have numerically lower BMIs than nonsmokers. 
Table 4 Comparison of total energy expenditure (kcal/d) by smoking status in males and females after controlling for the effects of age, fat-free mass, and self-reported physical activity

\begin{tabular}{llll}
\hline & Never smokers & Current Smokers & Difference \\
\hline Males & & & $91(p=0.24)$ \\
Adjusted for age and FFM & $2870+28$ & $2961+72$ & $111(p=0.15)$ \\
Adjusted age, FFM, and SR PA & $2867+27$ & $2979+71$ & $-81(p=0.16)$ \\
Females & & & $-81(p=0.15)$ \\
Adjusted age and FFM & $2334+24$ & $2252+51$ & $2252+51$ \\
Adjusted for age, FFM, and SR PA & $2334+24$ &
\end{tabular}

Values are given as least square mean +/- standard error of the mean. Age in years, FFM = fat-free mass in kg, and SR PA is self reported physical activity in mets*hour. The number of subjects is the same as in table 1.

This atypical BMI pattern may be due to behavioral differences between OPEN participants and that of other studies as the OPEN cohort was highly educated, (83\% with one year of college or more including $32 \%$ with post-graduate education), from the same geographic area (Bethesda, MD and surrounding communities) and likely had a high level of health consciousness related to volunteer bias. Thus it is possible that the OPEN current smokers may have smoked less than participants in other studies resulting in the atypical BMI pattern seen in males

While it is true that dietary reporting may be associated with under eating [42], this is only true for food records as subjects know they are being observed. The OPEN study, however, utilized FFQs and 24-hour dietary recalls. FFQs ask about intake the past year while recalls are unannounced and ask about intake "yesterday." Both may be subject to error and bias but not to under eating. Under eating, if it did exist, would have an effect on caloric intake but very minimal effect on total energy expenditure which is the endpoint of our study.

Our findings among female participants, however, are more typical in that the BMIs of current smokers were $1.6 \mathrm{~kg} / \mathrm{m}^{2}$ less than those of never smokers. The adjusted TEE was not only not greater than that of never smokers, but actually trended toward a lower value than those of never smokers $(\mathrm{p}=0.15)$ and thus

Table 5 Multiple Regression Coefficients for Factors Related to Total Energy Expenditure

\begin{tabular}{lll}
\hline & Coefficient estimation & p-value \\
\hline Males & & \\
Smoking & 111.9 & $\mathrm{p}=0.15$ \\
FFM & 43.6 & $\mathrm{p}<0.001$ \\
Age & -13.3 & $\mathrm{p}<0.001$ \\
SR PA & 0.05 & $\mathrm{p}=0.006$ \\
Females & & \\
Smoking & -81.8 & $\mathrm{p}=0.15$ \\
FFM & 45.0 & $\mathrm{p}<0.001$ \\
Age & -3.5 & $\mathrm{p}=0.21$ \\
SR PA & 0.01 & $\mathrm{p}=0.40$ \\
\hline
\end{tabular}

FFEM = Fat free mass. SR PA = Self reported physical activity. did not support a hypothesis that TEE is elevated in smokers.

Our TEE findings among the participants from the OPEN study do not support the hypothesis that smoking increases TEE. These findings differ from those found in NHANES in which clear differences in BMIs between smokers and nonsmokers were shown. Also, although this is the largest reported cohort of smokers who have TEE data as measured by the DLW method, the total number of current smokers was still only 47 individuals, thus power was limited.

These indicate that weight gain following smoking cessation is a result of increased caloric consumption versus decreased TEE, indicating that health practitioners should include dietary counseling in smoking cessation programs with an eye toward decreasing postcessation weight gain.

\section{Author details}

${ }^{1}$ Department of Endocrinology, School of Medicine and Public Health, University of Wisconsin, Madison, WI, USA. ${ }^{2}$ Department of Nutritional Sciences, University of Wisconsin, Madison, WI, USA. ${ }^{3}$ Catering and Conference Service, University of Wisconsin, Madison, WI, USA. ${ }^{4}$ Division of Cancer Epidemiology and Genetics, National Cancer Institute, National Institutes of Health, Department of Health and Human Services, Rockville, MD, USA. ${ }^{5}$ Division of Cancer Control and Population Sciences, National Cancer Institute, National Institutes of Health, Bethesda, MD, USA.

\section{Authors' contributions}

DPB drafted the manuscript. RPT, AFS and AS were involved in the conception of the study, conception and conduct of the OPEN Study, data interpretation, and manuscript preparation; DAS was involved in the conception of the study, analysis of doubly labeled water data, data interpretation, and manuscript preparation. ZZ and LAJ were involved in analysis of doubly labeled water data and data interpretation. All authors read and approved the final manuscript.

\section{Competing interests}

The authors declare that they have no competing interests.

Received: 10 June 2010 Accepted: 1 November 2010 Published: 1 November 2010

\section{References}

1. Williamson DF, Madans J, Anda RF, Kleinman JC, Giovino GA, Byers T: Smoking cessation and severity of weight gain in a national cohort. $N$ Engl J Med 1991, 324:739-45. 
2. LaRowe TL, Piper ME, Schlam TR, Fiore MC, Baker TB: Obesity and Smoking: Comparing Cessation Treatment Seekers with the General Smoking Population. Obesity 2009, 17(6):1301-1305.

3. Flegal KM, Troiano RP, Pamuk ER, Kuczmarski RJ, Campbell SM: The influence of smoking cessation on the prevalence of overweight in the United States. N Engl J Med 1995, 333(18):1165-70.

4. Albanes D, Jones DY, Micozzi MS, Mattson ME: Associations between smoking and body weight in the U.S. population: analysis of NHANES II. Am J Public Health 1987, 77(4):439-44.

5. Ward KD, Klesges RC, Vander Weg MW: Cessation of smoking and body weight. International textbook of obesity. Bj?ö?rntop P edition. Chichester, United Kingdom: Wiley \& Sons Ltd; 2001, 323-36.

6. Klesges RC, Winders SE, Meyers AW, Eck LH, Ward KD, Hultquist CM, Ray JW, Shadish WR: How much weight gain occurs following smoking cessation? A comparison of weight gain using both continuous and point prevalence abstinence. J Consult Clin Psychol 1997, 65(2):286-91.

7. Kruger J, Ham SA, Prohaska TR: Behavioral risk factors associated with overweight and obesity among older adults: the 2005 National Health Interview Survey. Prev Chronic Dis 2009, 6(1).

8. Parsons AC, Shraim M, Inglis J, Aveyard P, Hajek P: Interventions for preventing weight gain after smoking cessation. Cochrane Database Syst Rev 2009, 1.

9. Chiolero A, Faeh D, Paccaud F, Cornuz J: Consequences of smoking for body weight, body fat distribution, and insulin resistance. Am J Clin Nutr 2008, 87(4):801-9, Review.

10. Dallosso HM, James WP: The role of smoking in the regulation of energy balance. Int J Obes 1984, 8(4):365-75.

11. Hofstetter A, Schutz $Y$, Jequier E, Wahren J: Increased 24-hour energy expenditure in cigarette smokers. N Engl J Med 1986, 314(2):79-82.

12. Walker J, Collins LC, Nannini L, Stamford BA: Potentiating effects of cigarette smoking and moderate exercise on the thermic effect of a meal. Int J Obes Relat Metab Disord 1992, 16(5):341-7.

13. Stamford BA, Matter S, Fell RD, Papanek P: Effects of smoking cessation on weight gain, metabolic rate, caloric consumption, and blood lipids. Am J Clin Nutr 1986, 43(4):486-94.

14. Burse RL, Bynum GD, Pandolf KB, Goldman RF, Sims EAH, Danforth E: Increased appetite and unchanged metabolism upon cessation of smoking with diet held constant. Physiologist 1975, 18:157.

15. Moffatt RJ, Owens SG: Cessation from cigarette smoking: changes in body weight, body composition, resting metabolism, and energy consumption. Metabolism 1991, 40(5):465-70.

16. Jessen A, Buemann B, Toubro S, Skovgaard IM, Astrup A: The appetitesuppressant effect of nicotine is enhanced by caffeine. Diabetes Obes Metab 2005, 7(4):327-33.

17. Perkins KA, Epstein $L H$, Stiller RL, Fernstrom MH, Sexton JE, Jacob RG, Solberg R: Acute effects of nicotine on hunger and caloric intake in smokers and nonsmokers. Psychopharmacology 1991, 103(1):103-9.

18. Perkins KA, Epstein LH, Sexton JE, Solberg-Kassel R, Stiller RL, Jacob RG: Effects of nicotine on hunger and eating in male and female smokers. Psychopharmacology 1992, 106(1):53-9.

19. Trabulsi J, Schoeller DA: Evaluation of dietary assessment instruments against doubly labeled water, a biomarker of habitual energy intake. Am J Physiol Endocrinol Metab 2001, 281:E891-E899.

20. Haggarty P, McGaw BA: Non-restrictive methods for measuring energy expenditure. Proceedings of the Nutrition Society 1988, 41:365-374.

21. Schoeller DA, van Santen E: Measurement of energy expenditure in humans by doubly labeled water method. J Appl Physiol 1982, 53(4):955-9.

22. Warwick PM, Baines J: Energy expenditure in free-living smokers and nonsmokers: comparison between factorial, intake-balance, and doubly labeled water measures. Am J Clin Nutr 1996, 63(1):15-21.

23. Trumbo $P$, Schlicker $S$, Yates AA, Poos M: Dietary reference intakes for energy, carbohydrate, fiber, fat, fatty acids, cholesterol, protein and amino acids. Food and Nutrition Board of the Institute of Medicine, The National Academies. J Am Diet Assoc 2002, 102(11):1621-30.

24. Kipnis V, Subar AF, Midthune D, Freedman LS, Ballard-Barbash R, Troiano RP, Bingham S, Schoeller DA, Schatzkin A, Carroll RJ: Structure of dietary measurement error: results of the OPEN biomarker study. Am J Epidemiol 2003, 158(1):14-21, discussion 22-6.

25. Tooze JA, Schoeller DA, Subar AF, Kipnis V, Schatzkin A, Troiano RP: Total daily energy expenditure among middle-aged men and women: the OPEN Study. Am J Clin Nutr 2007, 86(2):382-7.
26. Subar AF, Kipnis V, Trojano R, Midthune D, Schoeller DA, Bingham S, Sharbaugh CO, Trabulsi J, Runswick S, Ballard-Barbash R, Sunshine J, Schatzkin A: Using intake biomarkers to evaluate to extent of dietary misreporting in a large sample of adults: the OPEN study. American Journal of Epidemiology 2003, 158:1-13.

27. Physical activity questionnaire from the 1999-2000 National Health and Nutrition Examination Survey. [http://www.cdc.gov/nchs/data/nhanes/spqpa.pdf], Accessed September 20, 2010.

28. Perkins KA: Effects of tobacco smoke on caloric intake. British Journal of Addiction 1992, 87(2):193-205.

29. Margetts BM, Jackson AA: Interactions between people's diet and their smoking habits: the dietary and nutritional survey of British adults. BMJ 1994, 308(6935):1042-3.

30. Cade J, Margetts B: Cigarette smoking and serum lipid and lipoprotein concentration. British Medical Journal 298:1312.

31. Fehily A, Phillips K, Yarnell J: Diet, smoking, social class, and body mass index in the Caerphilly Heart Disease Study. American Journal of Clinical Nutrition 1984, 40:827-833.

32. Haste FM, Brooke OG, Anderson HR, Bland JM, Shaw A, Griffin J, Peacock JL: Nutrient intakes during pregnancy; observations on the influence of smoking and social class. American Journal of Clinical Nutrition 1990, 51:29-36.

33. Jacobs DR, Gottenborg S: Smoking and Weight: the Minnesota Lipid Research Clinic. American Journal of Public Health 1981, 71:391-396.

34. Klesges RC, Eck LH, Isbell TR, Fulliton W, Hanson CL: The effects of smoking status on the dietary intake, physical activity, and body fat of adult men. American Journal of Clinical Nutrition 1990, 51:784-89.

35. Triosi RJ, Heinhold JW, Vokonas PS, Weiss ST: Cigarette smoking, dietary intake, and physical activity: effects on body fat distribution- The Normative Aging Study. American Journal of Clinical Nutrition 1991, 53:1104-11.

36. Westerterp KR, Goris AH: Validity of the assessment of dietary intake: problems of misreporting. Curr Opin Clin Nutr Metab Care 2002, 5(5):489-93.

37. Schoeller DA: Measurement of energy expenditure in free-living humans by using doubly labeled water. J Nutr 1988, 118(11):1278-89.

38. Perkins KA, Epstein LH, Stiller RL, Marks BL, Jacob RG: Acute effects of nicotine on resting metabolic rate in cigarette smokers. Am J Clin Nutr 1989, 50(3):545-50.

39. Wager-Sadr SA, Levine AS, Morley JE, Hoidal JR, Niewoehner DE: Effects of Cigarette Smoke and Nicotine on Feeding and Energy. Pharmacol. Biochem. Behav 1984, 32:389-95.

40. Perkins KA: Metabolic Effects of Cigarette Smoking. Journal of Applied Physiology 1992, 72(2):401-9.

41. Westerterp KR: Assessment of physical activity: a critical appraisal. Eur J Appl Physiol 2009, 105:823-8.

42. Goris A, Westerterp-Plantenga MS, Westerterp KR: Under eating and underrecording of habitual food intake in obese men: selective underreporting of fat intake. American Journal of Clinical Nutrition 2000, 71(1):130-134.

doi:10.1186/1743-7075-7-81

Cite this article as: Bradley et al:: Effect of smoking status on total energy expenditure. Nutrition \& Metabolism 2010 7:81.

\section{Submit your next manuscript to BioMed Central and take full advantage of:}

- Convenient online submission

- Thorough peer review

- No space constraints or color figure charges

- Immediate publication on acceptance

- Inclusion in PubMed, CAS, Scopus and Google Scholar

- Research which is freely available for redistribution 